\title{
Prácticas lectoras en una biblioteca pública de Lima: el caso de los niños lectores asiduos
}

\author{
CARMEN MARÍA SANDOVAL FIGUEROA* \\ ROSA CAROLINA LANDAVERRY GIL**
}

Pontificia Universidad Católica del Perú

Recibido el 09-11-2017; primera evaluación el 13 -12-2018; segunda evaluación el 24-01-2019; tercera evaluación el 22-02-2019; aceptado el 24-02-2019

\section{RESUMEN}

El artículo presenta los resultados de una investigación realizada en una biblioteca pública en Lima, donde se observó las prácticas lectoras de niñas y niños que frecuentaban de forma asidua la sala infantil durante los meses de agosto a diciembre 2016. Los resultados muestran que el nińo lector construye sus propias prácticas lectoras a consecuencia de la asiduidad a la sala, la mediación de lectura y su rol de actor dinámico como usuario de biblioteca. Las prácticas lectoras tienen componentes lúdicos, educativos y funcionales. En la medida en que el nińo deviene lector, las prácticas de lectura se van complejizando y adquieren otros matices. Las prácticas de lectura hacen que un niño usuario asiduo de la biblioteca adquiera con el tiempo el rol de mediador de lectura dentro de su comunidad.

Palabras clave: bibliotecas, infancia, lectura, mediación.

\section{Reading practices in a public library in Lima: the case of frequent child readers} AbSTRACT

This article shows the results of research carried out on a public library located in Lima where we observed the reading practices of children who were frequent users of the reading rooms during the months of August to December of 2016. The results indicate that the children develop their own reading practices because of the frequent use of the room, the participation of the literacy mediator, and their role as dynamic agents in the use of the library. The reading practices have components: a playful aspect, an educational aspect and a functional aspect.

\footnotetext{
* Docente del Departamento de Educación de la carrera de Educación Inicial. Interés por los temas de comunicación y lenguaje en la primera infancia, bibliotecas y literatura infantil, mediación de lectura, Trastorno del Espectro Autista. Correo: sandoval.cm@pucp.pe

"Egresada de la carrera de Educación Inicial de la Facultad de Educación de la Pontificia Universidad Católica del Perú. Correo: a20131977@pucp.pe
} 
As the child becomes a reader, reading practices become increasingly complex and acquire other characteristics. Reading practices allow children who are frequent users of the library to, in time, acquire the role of literacy mediators.

Keywords: libraries, infancy, reading, mediation.

\section{Práticas de leitura em uma biblioteca pública de Lima: o caso de crianças leitores assíduas \\ Resumo}

$\mathrm{O}$ artigo apresenta os resultados de uma pesquisa realizada em uma biblioteca pública em Lima, onde foram observadas práticas de leitura de crianças que frequentavam, de forma assídua, a sala de leitura durante os meses de agosto a dezembro do ano 2016. Os resultados mostram que a criança leitora, constrói suas próprias práticas de leitura em decorrência da assiduidade com que frequenta a sala de leitura, da mediação da leitura e de seu papel enquanto ator dinâmico e usuário da biblioteca. As práticas de leitura têm um componentes lúdicos, educativos y funcionais. À medida que a criança se torna um leitor, as práticas de leitura se tornam mais complexas, adquirindo outras nuances. As práticas de leitura, fazem que uma criança, frequentadora assídua da biblioteca adquire, com tempo, o papel de mediador de leitura.

Palavra-chave: bibliotecas, infância, leitura, mediação.

\section{INTRODUCCIÓN}

Patte (2008) sostiene que la biblioteca pública es un espacio de promoción de la lectura y de encuentro entre lectores. En el caso de las bibliotecas infantiles, la autora afirma que es fundamental repensar su rol como un espacio de formación y de encuentro, que permite que los nińos tengan acceso libre a diversos textos, puedan desarrollar el aprendizaje autónomo y contar con espacios de socialización entre pares en torno a las lecturas. Yubero (2015, pp. 9-10) explica que "la misión de las bibliotecas ha sido durante mucho tiempo y, aún hoy sigue siendo, satisfacer las necesidades de información, formación y ocio de los ciudadanos». Se concibe en la actualidad como «[...] un lugar de una apropiación íntima y autónoma de la cultura escrita» (Petite, 2008, p. 164). Munita (2014) destaca la función de la biblioteca como un espacio generador de actividades culturales que consolidan la ciudadanía. La investigación muestra las características de las prácticas de lectura desarrolladas por los niños en una biblioteca pública, así como las construcciones progresivas de las mismas en el caso de los niños que tienen la oportunidad de asistir frecuentemente a esta sala de lectura de libre acceso. 


\section{AnteCedentes de la inVestigación}

\subsection{La lectura como práctica social}

Se concibe la lectura como una práctica social porque es una experiencia personal y colectiva que nos sirve para comunicar, sus usos cambian dependiendo de los escenarios y del tiempo en que estas lecturas tengan lugar (Ferreiro, 2001). Cassany (2009) sostiene que desde «[...] una mirada sociocultural, leer es una actividad situada, enraizada en un contexto sociocultural, que está interrelacionada con otros códigos (habla, íconos), que se rige por relaciones de poder y que sirve para desarrollar las prácticas sociales de la comunidad» (pp. 17-18). Cajaio (2013) añade que el acto de saber leer sobrepasa el «ejercicio de asignar sonidos a unas letras para armar palabras que luego estructuran frases» (p.55) porque leer significa interpretar y contar con la capacidad de poder descifrar los significados a los que nos confronta un texto.

Reyes (2007) sostiene que, cuando un niño se familiariza con los libros desde temprana edad no solo descubre las imágenes sobre un papel sino también diversas representaciones del mundo en que vive y «las imágenes se van encadenando para construir historias» (p. 60). El acto de leer le transmite la idea de que la lectura es un acto social y cultural (Aliagas, 2009) ${ }^{1}$. Se comprende que las prácticas sociales del lenguaje son un conjunto de acciones como la lectura, la escritura y la oralidad, que se conciben y se construyen en circunstancias reales de comunicación, y que entran en funcionamiento con propósitos comunicativos (Rodríguez, 2014).

\subsection{La biblioteca pública infantil}

Es un espacio privilegiado donde acuden las personas para leer e informarse, producir escritos y estudiar. Como lugar de encuentro entre usuarios promueve las interacciones y los intercambios a través de múltiples actividades: tertulias literarias, la hora del cuento, conversatorios, entre otras (Salaberría, 2008). Patte (2008) considera que «en un mundo cada día más tecnificado, la biblioteca acentúa la comunicación humana, los lazos y las relaciones

\footnotetext{
1 La decisión de optar por abordar la noción de práctica lectora y no práctica letrada responde a que en la biblioteca estudiada se privilegia exclusivamente la lectura. Las observaciones mostraron que los niños no contaban con materiales para producir escritos a partir de lo leído, e inclusive, desde que ingresaban a la sala las mediadoras les indicaban que en ese espacio únicamente se podía leer. Como acción de escritura los niños anotaban su nombre y firmaban en una lista de registro de afluencia de públicos, esto se hacía como una acción ritualizada. Así, lectura y escritura están desvinculados en este espacio y se reconoce exclusivamente la función social de la lectura en la formación de lectores.
} 
interpersonales que se tejen en torno a la necesidad de saber, reconocerse y pensar» (p. 29). En la biblioteca hay espacio para la construcción de individualidades, así como para la formación de una comunidad (Petit, 2016) y «las bibliotecas no son solamente templos de la información; son también conservatorios de sentido» (Petit, 2008, pp. 176-177).

La biblioteca cumple un rol estratégico porque es el centro documental donde el ciudadano de cualquier edad se forma y aprende más allá de los «muros» de la institución escolar (Salaberria, 2008). Bonilla, Goldin y Salaberria (2008) explican que la formación de usuarios de biblioteca está orientada al desarrollo de competencias para comprender una amplia gama de textos, ser capaz de acceder a la información y procesarla eligiendo aquella que es más útil y que, además, se puedan producir textos relacionados con la información o las lecturas que se han realizado. Estas acciones permiten al usuario dialogar con diversos interlocutores, participar activamente y responder a las exigencias que demanda el mundo actual. La biblioteca es «una institución pública absolutamente imprescindible para ayudar a reducir las desigualdades sociales en el acceso de todos los ciudadanos a la información y al conocimiento, así como para el sostenimiento de las democracias» (Marlasca, 2015, p. 91).

En el caso de las bibliotecas infantiles, su rol es familiarizar a los niños con los materiales escritos y acercarlos a la cultura escrita a través de prácticas de lectura íntima y silenciosa que los construyen como lectores (Escardó, 2012). Deben brindar un espacio accesible para la lectura, en un ambiente agradable que los haga «sentir como en casa», teniendo libertad de elegir libros y acceso a la mediación de lectura que les permita crear interacciones entre ellos, así como con los mediadores, en un clima de respeto e igualdad (Patte, 2008). Reyes (2008) explica que cuando los niños acceden a la biblioteca infantil se constituye como parte de su cotidianidad, además que se familiarizan con diversas formas de leer y con el libro como un objeto cultural, así esta experiencia puede impactar su vida académica, así como otras esferas de su desarrollo personal, intelectual y afectivo.

Para Slaby (2014) la biblioteca infantil constituye un buscador no virtual de información abierto a la comunidad. En ese sentido, al interior de una biblioteca infantil desaparecen las estructuras y los límites marcados por la escolarización, y cobra protagonismo el juego, la palabra y el diálogo en un entorno amigable, flexible y rico en experiencias de aprendizaje para los jóvenes lectores. Patte (2008) sostiene que la biblioteca infantil debería ser una institución a la que se acude permanentemente, además de ser parte de las actividades de la vida cotidiana de los niños. Marlasca (2015) afirma que 
la manera de asegurar los hábitos de lectura en los niños se da a través de un proceso gradual y mediado por un adulto; además, se conectan prácticas lectoras que se desarrollan en la familia, en la escuela y en la biblioteca, de manera dialogada, tejiendo una red entre estos espacios. Las prácticas van cambiando las formas de leer de los usuarios porque se interactúa en una comunidad de lectores y se afianza la formación autodidáctica que el niño pueda realizar gracias a su experiencia como lector.

Se comprende la función de la biblioteca infantil como ente democratizador del acceso al mundo escrito porque permite que los niños de diversas edades, de diferentes condiciones socioeconómicas y culturales accedan a ella, y les brinda acceso a diversas experiencias cuando en las lecturas se funden la emoción y la afectividad, características indispensables de la mediación lectora con niños (Reyes, 2008) $)^{2}$. Alzola e Iturrioz (2016) sostienen que cuando los niños tienen acceso a las bibliotecas específicamente dirigidas a sus edades, entonces ejercen sus derechos como lectores y también como ciudadanos. Bonilla, Goldin y Salaberría (2008) afirman que la lectura tiene una «envoltura emocional» gracias a la mediación, se vincula lo escrito a lo afectivo, asociando de manera positiva las vivencias de la lectura y rompe con la idea de que los libros son un objeto inaccesible, extraño y amenazante.

\subsection{Las prácticas lectoras infantiles}

Reyes (2008) afirma que las prácticas lectoras infantiles están vinculadas con la familiaridad que tiene la persona con los libros como objeto cultural desde una edad temprana, la experiencia de la lectura compartida y en voz alta en los contextos familiares y escolares, así como el nivel de acceso que tenga a las bibliotecas públicas. Según la Casa de la Literatura Peruana y Minedu (2016), se debe considerar, además, la experiencia que tiene la persona para acceder a una diversidad de lecturas y las maneras en que las recepciona, así como la experiencia lectora que adquiere a lo largo del tiempo. Las prácticas lectoras se definen también por la ocupación de los espacios donde se realiza la lectura, los tiempos que se dedica a ella, las motivaciones del lector y los usos que hace de lo que lee.

Aliagas (2009) sostiene que «desarrollar la práctica lectora en espacios no escolares contribuye a consolidar el hábito lector» (p. 179). La autora afirma que las actividades de lectura y escritura son consideradas por el nińo como «relevantes»

\footnotetext{
2 Para conocer experiencias sobre bebetecas ver Jardín Espantapájaros (Colombia) http://espantapajaros.com/ o la bebeteca de la Casa de la Literatura (Perú) http://www.casadelaliteratura.gob. $\mathrm{pe} / \mathrm{p}=19826$.
} 
porque son las que utilizamos los adultos para comunicarnos y hacen parte de nuestra cultura. La familia juega un rol fundamental en este aspecto cuando promueve un espacio para desarrollar el hábito lector en los niños; sin embargo, esto no sucede sistemáticamente, entonces es importante que la biblioteca cree el espacio para conectarse con la familia e incluirla en sus actividades (Alzola e Iturrioz, 2016). Spedding, Harkins, Makin y Whiteman y otros (2007), haciendo referencia a las prácticas lectoras infantiles en el contexto familiar, sostienen que la lectura ocurre como una práctica social única marcada por las formas de leer, las creencias en torno a la lectura y el significado que tiene en la vida de los miembros más adultos. Los padres y los cuidadores de los niños menores de 6 años son usuarios expertos del lenguaje que transmiten y modelan prácticas lectoras propias de su entorno cultural y social, que suponen un conjunto de formas de hacer, reaccionar, interactuar y situarse frente a la lectura.

Para finalizar, se destaca que el lector construye sus propias prácticas de lectura gracias a las trayectorias personales y a sus experiencias, las cuales no son lineales, sino que van evolucionando (Ortega, 2006). Martin y Ebrahim (2016) sostienen que la práctica lectora permite que el nińo desarrolle capacidades de escucha activa y se mantenga concentrado en una lectura por un tiempo determinado, seleccione sus lecturas de manera autónoma, maneje un vocabulario acorde a su edad y se exprese con claridad, pueda repetir frases o diálogos de cuentos que ha leído o escuchado, lea imágenes, responda a textos orales, escritos y a las imágenes que los acompañan a través de emociones, gestos y/o palabras, aprenda vocabulario nuevo de las lecturas que realiza y las pueda aplicar en situaciones cotidianas, así como socializarlas con sus pares.

\subsection{La mediación de lectura}

Esta actividad puede definirse como un acto intencionado, programado, a largo plazo y como «toda forma de acción tendiente a promocionar la práctica cultural de la lectura» (Bonnacorsi citado por Munita, 2015, p. 41). El autor insiste en la importancia de la «no inmediatez» de las prácticas de mediación, así como «recordar que al inicio y al final del recorrido no es ni el texto, ni el lector, ni la lectura lo que nos interesa sino sus modos de realización y sus interacciones concretas» (Munita, 2015, p. 41). En este sentido, para el autor, las prácticas de animación y mediación de la lectura se diferencian por diversas razones, entre las que podemos destacar la inmediatez, así como el carácter efímero y homogeneizador de la primera; mientras que, en el caso de la segunda, el lector se percibe como un actor singular y el objetivo del mediador es que los niños establezcan relaciones más significativas y duraderas con la lectura. 
El rol de mediador se construye a partir de «[...] su propia actitud con los objetos que están en la biblioteca, por sus gestos, sus sugerencias, por su voz, por las historias que van a leer, podrán volver deseable la apropiación de la cultura escrita - a condición, por supuesto, de que ellos mismos tengan curiosidad por el mundo y disfruten de la compañía de los libros» (Petite, 2008, p. 166). Aliagas (2009) afirma que, en el caso de los niños, la participación activa del acompañante-mediador de lectura es indispensable en el proceso para que accedan a los libros y las lecturas. Además, la autora destaca la importancia del vínculo que se crea entre el niño y el mediador porque en «esta interacción niño-adulto se negocian significados verbales, literarios y socioculturales que promueven su crecimiento cognitivo como lectores y miembros de una comunidad» (Aliagas, 2009, p. 176).

En cuanto a la actividad de la mediación de lectura en voz alta, Reyes (2007) afirma que el vínculo entre los nińos y la lectura se establece gracias a las características de la voz humana que es un recurso significativo que genera la emoción. Ferreiro (2011) sostiene que la lectura en voz alta permite que los niños desarrollen la oralidad formal porque descubren que leer es un «acto mágico»: «Alguien mira formas extrañas en la página, y de su boca «sale lenguaje»: un lenguaje que no es de todos los días, un lenguaje que tiene otras palabras y se organiza de otra manera» (pp. 121-122). Petite (2008) sostiene que el libro y la voz se funden porque la biblioteca es un espacio que fomenta la oralidad cuando hay un programa de mediación sostenido.

\section{Metodología de eSTUdio}

La investigación tiene un enfoque cualitativo y se trata del estudio de caso. La biblioteca se encuentra ubicada en el Centro Histórico de la ciudad de Lima, en un distrito turístico y concurrido. La elección del espacio responde a su ubicación, es accesible y convoca a público, sobre todo, los fines de semana. El objetivo general de la investigación fue describir las prácticas lectoras de los públicos que frecuentan la biblioteca pública infantil. Entre los objetivos específicos referidos a los lectores asiduos se destaca: (i) identificar los perfiles de lectores de los públicos de la biblioteca pública infantil y (ii) identificar las prácticas de lectura de los usuarios asiduos de la biblioteca pública infantil.

El público de lectores asiduos lo conforman: (i) los niños que viven en un condominio que está ubicado al costado de la biblioteca, (ii) los hijos de los comerciantes que tienen un puesto de venta en los alrededores de la biblioteca y (iii) los hijos de las vendedoras ambulantes que no cuentan con un puesto fijo y que se desplazan de manera itinerante por la Plaza de Armas de Lima. 
En este grupo se encuentran los niños de menor edad (3-6 años), que recurren al espacio porque conocen a las mediadoras y les atraen los libros ${ }^{3}$. Las categoría lector asiduo designa a los nińos que frecuentan la sala con regularidad, al menos 3 veces por semana, durante un espacio mínimo de una hora.

Para identificar las prácticas lectoras de los públicos, se utilizaron las técnicas de la observación y la entrevista a las mediadoras. En el caso de los lectores ocasionales, se complementó la información con una encuesta a padres (nótese que esa categoría de usuario no es objeto de este artículo). Las observaciones tuvieron una duración de cuatro meses y se visitó la sala quincenalmente, durante los sábados por la tarde, con una duración de visita de un promedio de dos horas. Las observaciones nos permitieron identificar las acciones que realizaban los niños en la sala, por ejemplo: explorar los textos, solicitar una lectura en voz alta a la mediadora o a sus acompañantes, leer de manera colaborativa, interesarse por los libros nuevos, uso del espacio y criterios de selección de los libros. Estas acciones se registraron con apoyo de una guía semiestructurada. Las entrevistas fueron realizadas a las tres mediadoras que realizaban la gestión de la sala, permitiéndonos conocer el perfil de los públicos, reconocer las prácticas de lectura de los niños, así como las formas de mediación.

\subsection{Características de la sala donde se realizó el estudio}

La biblioteca infantil estudiada es de gestión pública y la administra La Casa de la Literatura Peruana. La sala se inauguró el 15 de noviembre del 2014 y lleva su nombre en honor a la escritora peruana Cota Carvallo ${ }^{4}$. Entre las características físicas, se pudo observar que está compuesta por un solo ambiente, en forma rectangular y se subdivide de manera intrínseca en tres subespacios: la recepción y dos espacios de lectura. La sala alberga cuatro colecciones de libros: primeros lectores (Pájaro niño, etiqueta amarilla), lectores intermedios (Oshua y el duende, etiqueta roja), lectores avanzados (Rutsí el pequeño alucinado, etiqueta verde) y los libros informativos (La Flor del tiempo, etiqueta celeste). El acervo es de 1500 libros expuestos en sala, la estantería es abierta y accesible a los niños, los materiales han sido seleccionados con rigurosidad y sobre la base de un protocolo de calidad del texto que tiene la biblioteca, las actividades de mediación de lectura son variadas y no están centradas únicamente en la figura del mediador ${ }^{5}$.

3 En el caso de los hijos de las vendedoras ambulantes, las familias vienen de provincia y algunos de ellos son migrantes estacionales.

4 Para mayor información sobre la sala véase: http://www.casadelaliteratura.gob.pe/?page_id=17448

5 Los programas son variados y pueden incluir cuentacuentos, lectura de textos en voz alta y compartida, sesiones de creación o crítica literaria, narraciones de los Abuelos Cuentacuentos, entre otras. La 
El acervo es mayoritariamente de libros impresos, pero lo interesante es que varían en el formato ${ }^{6}$. El funcionamiento de la sala permite que los niños se fidelicen gracias a la mediación de lectura y la formación de una comunidad de lectores que los acoge y es amigable con ellos.

\section{Resultados}

Se presentarán los perfiles de los públicos que asisten a la sala y la construcción de las prácticas de lectura identificadas en el caso de los lectores asiduos.

\subsection{Perfiles de los públicos de la sala estudiada}

Las mediadoras de la sala han podido identificar tres públicos: los lectores asiduos, las familias con niños y los grupos de colegio ${ }^{7}$. La acogida a los públicos varía en función de las características de cada grupo y sus necesidades. Estas diferencias también impactan en el desarrollo de las mediaciones de lectura, en la libertad que tiene el niño para elegir su lectura y en la intervención de las mediadoras para orientar las lecturas de los niños (dependiendo de si está acompañado o no). La denominación «lector asiduo» es una etiqueta utilizada para categorizar al público que asiste frecuentemente a la sala, un nińo o una niña entre 3 y 12 ańos que asiste a leer solo o con un acompañante, tanto los días laborables como los fines de semana. Las mediadoras afirman que la frecuentación de los niños a la sala hace que ellas los identifiquen fácilmente por sus nombres, perciban su presencia y los nombren de manera coloquial como los caseritos.

El lector asiduo es percibido como ávido por aprender, cautivado por lo nuevo y con gusto por la lectura. Es un niño que interactúa permanentemente con las mediadoras y con otros lectores asiduos que se encuentra en la sala; además, manifiesta sus emociones en torno a la lectura. La asiduidad implica también que las mediadoras puedan conocer más a estos nińos y relacionarse con ellos de manera más cercana, escuchan sus historias y los ven crecer como lectores. El nivel de asiduidad varía de lector a lector y esto impacta también

\footnotetext{
promoción de la lectura también es realizada con la visita de autores o ilustradores a la sala, además de conversatorios que se realizan a partir de estas visitas.

6 Los formatos varían principalmente en tamaño, colores y forma. Los libros pueden presentarse en formato de encarte, de láminas, desplegable, pop-up, tela, etc.

7 La información sobre los tipos de públicos que frecuentan la biblioteca ha sido sistematizada de las entrevistas a las mediadoras de la sala.

8 En el Perú, el término casero hace referencia a un parroquiano, a una persona que acostumbra ir a comprar repetidas veces a un mismo lugar. DRAE, http://dle.rae.es/?id=7oNbEls.
} 
en su relación con la sala, la lectura, las mediadoras y los otros niños, tal como veremos más adelante.

El siguiente público son los niños que vienen acompañados de sus familias, principalmente los fines de semana y se trata de un público heterogéneo que frecuenta la sala mayoritariamente por primera vez. Las mediadoras perciben que hay diferentes formas de acercamiento de las familias a la sala y hay variaciones en la permanencia de este tipo de público en función del interés que muestra el niño por la lectura. La biblioteca no siempre es percibida como tal por este público: «en el caso de familias, preguntan si es gratuito, les parece extraño, incluso, el espacio y que sea gratis. Porque siempre es la pregunta: «¿Cuánto está? Y ¿Cómo accedo? ¿Tengo que sacar carnet? Y se le explica que no, que es totalmente libre [...]» (Mediadora 1, entrevista, sábado 24 setiembre del 2016).

El tercer público está conformado por los grupos de estudiantes de colegios de los niveles de inicial y primaria, tanto de instituciones educativas estatales como privadas ${ }^{9}$. La visita es promovida a iniciativa de una maestra o del colegio, las mediadoras los acogen y les muestran el funcionamiento de la sala, las normas de convivencia y realizan una actividad de mediación de lectura. En general, las mediadoras trabajan junto al docente acompañante. Cuando los niños no han tenido la experiencia de conocer una biblioteca, muestran desconocimiento sobre las formas de lectura en ella (cómo se lee, cómo se usan los libros, cómo se comparte el material), las mediadoras brindan el acceso al espacio de lectura y, a su vez, van incorporando normas de convivencia necesarias para la vida cotidiana de la sala.

A partir de las observaciones, se han definido criterios que sirven para identificar los perfiles de lectores de la sala:

Durante las observaciones que realizamos pudimos identificar que existía una división en la categoría lectores asiduos según el acompañamiento que tenía el niño:

- Lector asiduo sin compañía de un cuidador

- Lector asiduo con compañía de un cuidador o de otros niños

9 La investigación que realizamos no indagó en las prácticas lectoras de niños que asistían a la sala en el marco de las visitas de colegio. Nuestro interés se centró en conocer las prácticas lectoras de los niños que asistían de manera opcional a este espacio. 
Prácticas lectoras en una biblioteca pública de Lima: el caso de los niños lectores asiduos

Tabla 1. Criterios para establecer perfiles de lectores de la biblioteca pública infantil estudiada

\begin{tabular}{|c|c|}
\hline Criterios & Descripción \\
\hline Edad del niño & $\begin{array}{l}\text { Define modalidad de acceso a la sala (acompañado/no } \\
\text { acompañado) } \\
\text { Define tipos de lecturas }\end{array}$ \\
\hline Lugar de procedencia & Procedencia del nińo según domicilio \\
\hline Frecuencia de asistencia & Número de días que asiste a la sala semanalmente \\
\hline Lugar de lectura del niño & $\begin{array}{l}\text { Lugar o espacio donde los niños prefieren leer cuando están } \\
\text { presentes en la sala }\end{array}$ \\
\hline Familia & $\begin{array}{l}\text { Características de las familias del niño } \\
\text { Formas de acompañamiento en la lectura }\end{array}$ \\
\hline Demanda de mediación & Tipo de solicitud \\
\hline Elección de la lectura & $\begin{array}{l}\text { Posibilidades en la libertad de elección y de lectura de un libro. } \\
\text { Persona que realiza la elección }\end{array}$ \\
\hline
\end{tabular}

Elaboración propia sobre la base de las observaciones realizadas en la biblioteca. Los criterios permiten identificar los perfiles de lectores que acuden a la sala de lectura.

En las tablas 2 y 3 , se presentan las características de cada perfil de lector asiduo.

En síntesis, la diferencia entre un lector asiduo con o sin compañía está definida por tres criterios importantes: (i) el rol del sujeto mediador, (ii) la libertad que tiene el niño para desplazarse en el espacio y (iii) las posibilidades de elección de un libro. Se observó que las mediadoras tienen disposición de escucha atenta, brindan oportunidad al niño para que explore el espacio y los libros, muestran apertura para orientar la elección del libro dando autonomía al niño en la búsqueda de libros predilectos o temáticas específicas.

En el caso de los acompañantes, se encuentran ciertos matices en el cumplimiento del rol mediador que se influencia por sus creencias personales sobre la elección de la lectura y el criterio fundamental es la edad: «mi niño tiene 8 ańos ¿Qué libro puede leer?» (Mediadora 1, entrevista, sábado 24 de setiembre del 2016). Otro factor lo determina el espacio que consideran "como adecuado» para realizar la lectura, la mirada del adulto es la norma para el uso del mobiliario y de los espacios de la sala; por ejemplo, las mesas y las sillas constituyen el único lugar adecuado para lectura. 
Carmen María Sandoval Figueroa, Rosa Carolina Landaverry Gil

Tabla 2. Perfil del lector asiduo sin compañia de un cuidador

\begin{tabular}{|c|c|}
\hline Criterios & Descripción \\
\hline Edad del niño & Entre 3 y 12 años. \\
\hline Lugar de procedencia & $\begin{array}{l}\text { Viven en el condominio. } \\
\text { Hijos de los comerciantes ambulantes y con puesto fijo. }\end{array}$ \\
\hline Frecuencia de asistencia & $\begin{array}{l}\text { Aproximadamente } 4 \text {, pero puede variar según ciclo estacional } \\
\text { (periodo escolar, vacaciones, fiestas, feriados porque la asi- } \\
\text { duidad aumenta). }\end{array}$ \\
\hline Lugar de lectura del niño & $\begin{array}{l}\text { No está definido porque utilizan todos los espacios de la } \\
\text { sala. Prefieren estar parados o arrodillados en la silla, se } \\
\text { desplazan libremente por la sala. }\end{array}$ \\
\hline Familia & $\begin{array}{l}\text { Se tiene muy poco conocimiento de la familia del niño. } \\
\text { Los miembros de la familia del nińo no participan en los } \\
\text { procesos de mediación de lectura. }\end{array}$ \\
\hline Demanda de mediación & $\begin{array}{l}\text { Solicitan permanente acompañamiento de la mediadora en } \\
\text { la lectura. } \\
\text { Las demandas de mediación son diferentes según edad. } \\
\text { Los nińos menores de } 6 \text { ańos solicitan la lectura en voz alta } \\
\text { casi exclusivamente. } \\
\text { Los nińos mayores de } 6 \text { años, además de la lectura, solici- } \\
\text { tan conversaciones sobre la lectura u otros temas. }\end{array}$ \\
\hline Elección de la lectura & $\begin{array}{l}\text { Las mediadoras dan completa libertad para la elección y } \\
\text { lectura de un libro. Pueden brindar orientaciones o suge- } \\
\text { rencias a demanda del niño. } \\
\text { El niño es el que realiza la elección del libro. }\end{array}$ \\
\hline
\end{tabular}

Elaboración propia elaborada sobre la base de las observaciones realizadas en la biblioteca.

Por último, otro factor es la naturaleza que se le concede al valor de la experiencia de la lectura que se considera que tienen los niños y sus capacidades para procesar la información como lector. Esta situación determina el grado de participación del acompañante, que fluctúa en un espectro que va desde un acompańamiento intenso, en el cual el niño participa activamente y un acompañamiento nulo, dejando al niño leer solo. Cuando la mediación es nula, el acompańante se limita a observar la sala, leer el periódico, su celular u otro libro que ha cogido de los estantes de la sala. Deja que el niño se entienda 
Tabla 3. Perfil del lector asiduo con compañía de un cuidador

\begin{tabular}{ll}
\hline Criterios & Descripción \\
\hline Edad del niño & Entre 1 y 12 años. \\
Lugar de procedencia & $\begin{array}{l}\text { Viven en el condominio o sectores aledaños (Por ejemplo: } \\
\text { Lima Cercado, San Juan de Lurigancho). }\end{array}$ \\
Frecuencia de asistencia & $\begin{array}{l}\text { 1 o 2 veces a la semana, pero puede variar según ciclo esta- } \\
\text { cional (periodo escolar, vacaciones, fiestas, feriados). }\end{array}$ \\
Lugar de lectura del niño & $\begin{array}{l}\text { En las sillas y mesas, se ubican cerca al acompañante. En gene- } \\
\text { ral se sientan u ocupan un lugar definido en la sala. }\end{array}$ \\
Familia & $\begin{array}{l}\text { Se tiene muy poco conocimiento de las familias. } \\
\text { Solicitan poco acompañamiento de la mediadora en la lec- } \\
\text { tura. El rol de mediador está centrado en el padre de familia } \\
\text { o en el acompañante. }\end{array}$ \\
Son orientadas por el acompañante teniendo como referen- \\
cia la edad del niño. \\
Elección de la lectura
\end{tabular}

Elaboración propia elaborada sobre la base de las observaciones realizadas en la biblioteca.

con el libro así se le dificulte la lectura. En cambio, cuando el protagonismo del acompańante es fuerte se puede dar en dos formas. Por ejemplo, se solicita que el niño participe activamente en la lectura, lea de manera compartida con el acompañante e interactúen durante el proceso de mediación; pero también, el efecto perverso que puede suceder es ubicar al niño como un receptor pasivo y observador silencioso en el momento de la lectura cuando el mediador se torna como único protagonista de la misma (observaciones realizadas en la sala a lo largo de las visitas).

En la siguiente tabla se presentan algunas precisiones sobre tipos de lectura identificados con respecto al tipo de lector asiduo y su impacto en el tipo de mediación que recibe el niño: 
Tabla 4. Relación entre el tipo de lector asiduo, las formas de lectura y la mediación

\begin{tabular}{|c|c|}
\hline Frecuentación & Tipos de lectura identificados \\
\hline $\begin{array}{l}\text { Usuario frecuente/ lector asiduo } \\
\text { sin acompańante }\end{array}$ & $\begin{array}{l}\text { Eligen sus lecturas o solicitan recomendación } \\
\text { Lectura mediada por pares o mediadora } \\
\text { Lectura autónoma } \\
\text { Lectura colectiva } \\
\text { Leen por sí mismos y le leen a otros } \\
\text { Lectura repetida de un mismo texto } \\
\text { La lectura es una práctica que crea vínculos dentro } \\
\text { de la comunidad de lectores }\end{array}$ \\
\hline $\begin{array}{l}\text { Usuario frecuente/ lector asiduo } \\
\text { con un acompañante }\end{array}$ & $\begin{array}{l}\text { La elección de la lectura es más restringida, pero } \\
\text { depende de la libertad que le otorgue el acompañante } \\
\text { Lectura mediada por el acompañante } \\
\text { Lectura autónoma } \\
\text { Leen por sí mismos y le leen a otros }\end{array}$ \\
\hline
\end{tabular}

Elaboración propia elaborada sobre la base de las observaciones realizadas en la biblioteca.

\subsection{Prácticas lectoras de niños asiduos a la biblioteca}

Las prácticas de lectura tienen un componente lúdico, educativo y funcional. Son lúdicas porque pueden ser una forma de jugar y recrearse. Son educativas porque implican aprendizaje a nivel de los códigos de la sala y de los contenidos de los libros. Son funcionales porque se usan dentro y fuera de la sala, entonces tienen un impacto en la vida de los niños. Las prácticas evidencian que el interés de los niños está centrado, sobre todo, en la lectura de textos de literatura infantil y en un descubrimiento de temas que no conoce. En menor medida acuden a la sala para consultar textos que les pueden ayudar a realizar tareas escolares.

En las prácticas lectoras en la biblioteca estudiada hay ciertas acciones que permiten identificar cómo leen los lectores asiduos en función de tres categorías: (i) el uso que hacen del espacio, (ii) la manera cómo eligen las lecturas y (iii) las formas de leer que han creado dentro de su comunidad de lectores. Las categorías están interrelacionadas dado que la elección de un texto se realiza con un propósito y define maneras de leer. Por ejemplo, la elección de la lectura le demanda explorar los estantes porque está en búsqueda de un libro para leer con un amigo, eso determina el uso del espacio porque deben decidir si leen 
sentados o parados, en la mesa o sobre los puffs; pero, además, determina las maneras de leer porque en este caso leerán de manera colectiva y no individual (observaciones realizadas en la sala a lo largo de las visitas).

Las prácticas lectoras que construye el lector asiduo son resultado de su experiencia de frecuentación de la sala. Se trata de un sentido de apropiación del espacio y las colecciones, de una relación significativa que el niño ha establecido con el libro y las mediadoras: «[...] tienen esos momentos de apropiación con el libro, que no quieren que alguien más lo toque» (mediadora 2, entrevista, 10 septiembre de 2016). El lector asiduo ha desarrollado el sentido de pertenencia a una comunidad, de manera que se compromete para preservar el buen funcionamiento de la sala, la conservación de los libros y su relación con las mediadoras y las personas que visitan el espacio. El sentido de apropiación le permite hacer uso del espacio de manera conveniente, de explorar el mobiliario y las colecciones, los estantes y los libros, respetando el orden de la sala e interiorizando las normas de convivencia. La apropiación hace referencia a la emoción que significa para el nińo lector participar en una actividad de mediación de lectura, así como la afectividad que establece con la sala, los libros y las mediadoras. En ocasiones, el niño se convierte en un mediador y es él el que hace la lectura a otros niños que visitan la sala por primera vez: «también imitan lo que nosotros hacemos, que ellos también quieren leerles a los más pequeños, pero también en las actividades, empiezan a darles la bienvenida a las familias (mediadora 1, entrevista, 24 septiembre de 2016).

Con respecto al uso del espacio, las mediadoras explican que los niños perciben a la sala como un espacio nuevo que ofrece una variedad de libros y que brinda apertura para la libre elección de sus lecturas. Las características físicas de la sala, la disposición del mobiliario, su ambientación y el color blanco de las paredes generan en los niños una curiosidad, «[...] que los impulsa a querer conocer más y permanecer en la sala» (mediadora 2, entrevista, 10 septiembre de 2016). Existe una diferencia en el caso de los lectores asiduos porque hay niveles de asiduidad entre ellos, que es más visible entre los que frecuentan la sala casi a diario y los que solo asisten los fines de semana. En ambos casos, los niños se desplazan por los estantes en búsqueda de sus libros y un espacio para leer, pero en el primer caso los niños pueden utilizar cualquier espacio de la sala para leer y aseguran su comodidad de manera creativa porque esta seguridad para movilizarse en la sala se las brinda el conocimiento que tienen de este espacio. Por el contrario, en el caso de los lectores asiduos que solo asisten los fines de semana, los niños utilizan con mayor frecuencia las mesas o los puff tratando de ajustarse a las normas de la sala con las que se están familiarizando (observaciones realizadas en la sala a lo largo de las visitas). 
La exploración de los estantes y los libros es una etapa previa y necesaria del proceso de elección de un libro que ocurre como un comportamiento repetitivo en los diferentes tipos de lectores, en algunos casos está vinculado al desconocimiento de los materiales de la sala y, en otros, a la necesidad misma de explorar un material nuevo o conocido: «El nińo A llega corriendo, se dirige al estante de cuentos para nińos, elige un libro de manera aleatoria, mira la contraportada, lo coloca en el estante, prosigue explorando otros libros» (observación, 27 agosto de 2016). En un primer momento, la exploración no es intencional, se realiza de manera aleatoria entre los estantes, pero se respeta el orden de los libros porque se reconoce su ubicación y la norma de que todo libro que sale del estante debe volver a él después de ser leído. El niño interpreta los símbolos de codificación colocados por las mediadoras en los libros (colores), busca estos símbolos en los estantes y ordena según la clasificación que se ha establecido en la sala: «Niña $\mathrm{B}$ se dirige al estante amarillo, coge un libro, lo abre y revisa página por página y lo coloca en su lugar. Repite la misma acción con otros libros (observación, 15 septiembre de 2016). Entonces, identificamos la primera práctica lectora: la exploración cinética ${ }^{10}$. El principal medio de conexión son el cuerpo, las manos y los desplazamientos que le permiten al niño conocer las colecciones y apropiarse de los libros y de la sala. Cuando el niño explora, su atención se centra a nivel del formato, en las características físicas del libro y las sensaciones que le produce entrar en contacto con él.

Las mediadoras identifican que la necesidad de una exploración cinética se presenta con mayor frecuencia en los niños de menor edad (entre 3 y 6 años) porque se encuentran permanentemente en proceso de descubrir el acervo de la sala. En cambio, los lectores asiduos mayores (más de 8 años) tienen la percepción de conocer el fondo de la sala, por lo que les resulta difícil distinguir las novedades, y suelen solicitar de manera explícita y directa que requieren un libro nuevo o diferente. Como afirma la mediadora 3, los niños utilizan la frase «yo ya me leí todo» (entrevista, 15 octubre de 2016).

A medida que el niño se entrena en sus formas de exploración va desarrollando habilidades como usuario de biblioteca que le permiten orientar su búsqueda a través de los estantes, sabe cómo discriminar las etiquetas y reconocer aquella que corresponde a su nivel de lectura y preferencia, siendo elementos orientadores de la elección. El niño asocia el color de las etiquetas

\footnotetext{
10 En un inicio de la investigación se denominó a este tipo de exploración como errática. Sin embargo, luego de la presentación de los hallazgos en el X Seminario de Investigación Educativa CISE-PUCP (Setiembre 2017), se ha redefinido el término a exploración cinética siguiendo la recomendación del bibliotecólogo Daniel David Arroyo Gonzáles, quien fue comentarista de la Mesa de Discusión sobre prácticas lectoras.
} 
amarilla, verde y roja a las colecciones de ficción y la etiqueta celeste a la colección de libros informacionales, por ejemplo. Una vez que el niño ha interiorizado este repertorio de variación de los colores de las etiquetas, comienza a orientar su exploración y hacerla cada vez más intencionada. Recién a este nivel, con su experiencia de lector, se puede considerar que el niño tiene un conocimiento básico del funcionamiento de la sala y la distribución de los libros en los estantes, de manera que la exploración intencionada es la segunda práctica de lectura identificada. Independientemente de la edad del niño, es la frecuentación a la sala la que influye en el desarrollo de estas habilidades, necesarias en la etapa inicial de la lectura en biblioteca. Por ejemplo, la mediadora 1 afirma que la exploración va más allá que simplemente mirar el libro y su portada, sobre todo la exploración implica una búsqueda minuciosa del contenido del libro y esta búsqueda se inicia muchas veces a nivel de la exploración de los formatos: «Porque tocan el libro, interactúan con él, lo intercambian, lo revisan, se ríen, o sea, están ahí. Porque entiendo que, para muchos de ellos, los formatos son totalmente nuevos, que para quién ya los conoce» (entrevista, 24 septiembre de 2016).

La práctica de la exploración intencionada varía en función del tipo de lector. En el caso de los lectores asiduos sin acompañante, desarrollan mayores habilidades: la búsqueda de lecturas predilectas y el conocimiento de material nuevo. Por ejemplo, «niña C solicita a la mediadora un libro que le gusta mucho y que está en doble dialecto (español-quechua), ubica el estante» (observación, 21 octubre de 2016). Las lecturas son elegidas como predilectas porque el niño conoce el material, lo ha seleccionado previamente en más de una ocasión y vuelve a él para abordarlo de manera diferente a través de una indagación continuada que se extiende a consecuencia de sus repetidas visitas a la sala y que se va enriqueciendo con cada experiencia de exploración. Cuando han llegado mediadoras nuevas a la sala han encontrado que los lectores asiduos no acompañados necesitan pasar por el proceso de exploración intencionada para ir en busca de sus lecturas favoritas. El conocimiento de material nuevo significa ir en búsqueda lecturas que se consideran atrayentes: «Ella se identifica más con ciertos libros. O sea, los pequeñitos. No se lo sentirá más fácil de usar. Entonces, así, ella tiene sus preferidos. O también los nuevos que han llegado, grandes, informativos, del cuerpo humano, de animales, de astronautas, del viaje el espacio. Esos también le llaman la atención porque tienen imágenes grandes y dentro tienen tarjetitas» (mediadora 3, entrevista, 15 de octubre de 2016).

Los niveles altos de exploración cinética e intencionada que se permiten en la sala promueven el ejercicio libre de la lectura, como lo sostiene la mediadora 2: «[...] nosotros no imponemos al nińo que lea algo, sino que él mismo tiene 
la posibilidad de sacar el libro que él vea que le guste más o que la imagen le atraiga más y poder sentarse. Elegir en qué mesa sentarse, elegir en qué silla sentarse y apreciar el libro» (entrevista, 24 septiembre de 2016). El niño no siente presión inmediata para elegir un libro ni para leer, sino que se respeta su curiosidad por descubrir y crear una relación con el libro que se facilita por el vínculo que establece el niño con un autor, un personaje, las ilustraciones o el mismo texto cuando puede leerlo él solo o cuando disfruta de una lectura mediada por otros. Así, el vínculo que se establece con un título, con un autor o un ilustrador es la tercera práctica de lectura en el repertorio de prácticas de un niño lector. El reconocimiento de un autor y de preferencias hacia su obra es una forma de estrechar lazos entre el autor y el lector: «Nińo E entra en la sala buscando Andrez Nuez de José Watanabe. El niño reconoce la portada y título» (observación, 19 noviembre de 2016).

A pesar de que se respeta el proceso de exploración autónoma del niño, es necesario considerar paralelamente una orientación a demanda, sobre todo cuando el niño muestra desinterés o indecisión para acercarse a los estantes o cuando considera que conoce todo el fondo de la biblioteca y necesita un apoyo para explorar los textos de una manera diferente. Este reconocimiento de la necesidad de orientación para la elección y la lectura de un libro es la cuarta práctica lectora: «al llegar a la Sala, la nińa F le solicitó a la mediadora que por favor la lleve al lugar en el que se encontraba la colección de libro del «Chimoc el perro peruano y sus amigos» porque es la colección que siempre lee desde su primera visita» (observación, 30 octubre de 2016). El rol del mediador es muy complejo porque la mediación consiste en "estar» $\mathrm{y}$ «no estar» presente en este proceso (mediadora 2, entrevista, 24 septiembre de 2016).

En el caso de los nińos que vienen acompańados de sus familias, las formas de exploración varían en función del sujeto que explora, sea el niño o el acompañante. Los niños pueden acercarse al estante, observar durante momentos prolongados y seleccionar algunos libros para explorar, se dirigen frecuentemente a sus padres para pedir consejo y solicitarles que asuman el rol de mediador. En general, son los adultos quienes solicitan asesoría puntual de parte de la mediadora para realizar la exploración e inclusive para elegir un libro: «[...] no he escuchado tanto con los lectores asiduos, por ejemplo: "¿qué me recomienda leer?». No he escuchado eso, pero sí con las familias, sí con los niños visitantes, ¿señorita que puedo leer?» (mediadora 1, entrevista, 10 septembre de 2016).

La demanda de orientación genera que los padres apliquen una suerte de restricción en la selección de los libros para sus hijos, ciñéndose a la edad como criterio primordial para la elección, limitando las posibilidades de ejercicio libre de la lectura que demandan sus hijos: «los padres por más que se diga que pueden 
coger la que quieran, ellos los ciñen a «iNo!;No!; No! Tú solo la etiqueta amarilla» o «tú solo la etiqueta roja» (mediadora 1, entrevista, 24 septiembre de 16).

Se aprecia que, en general, los lectores asiduos tienen más posibilidades de realizar una exploración libre y completa de los libros, lo que les permite realizar el ejercicio libre de la lectura, la quinta práctica lectora identificada. Los niños que asisten acompañados suelen ser guiados por otros y no ejercen en su totalidad su rol de lector. Esta situación los lleva a desempeñarse como lectores pasivos, teniendo que pedir permiso permanentemente para explorar y elegir, a consecuencia del desconocimiento del acompańante sobre la importancia que tiene la exploración en el proceso lector. El acompañante no reconoce a la exploración como el primer paso para la elección de un libro y su posterior lectura: «la mamá seleccionaba los libros para el niño J, mientras él trataba de acercarse al estante» (observación, 10 diciembre de 2016).

La exploración también es necesaria para que los niños que perciben un avance en su nivel de lectura puedan elegir textos más complejos, este cambio en la elección se cristaliza cuando un niño considera que puede leer libros de otra colección; por ejemplo, el niño L solía leer un libro de etiqueta amarilla y demanda a la mediadora su consejo para elegir una pequeña novela del estante rojo» (observación, 25 noviembre de 2016). La complejidad reside en el aumento de la extensión del texto y sus formas narrativas, la aparición de palabras nuevas y el género. La percepción del niño sobre un avance en su nivel de lectura es la sexta práctica de lectura que se ha identificado. Esta percepción está relacionada con la curiosidad que manifiesta por conocer otros tipos de texto y de temáticas. Según la mediadora 1, la evolución en los niveles de lectura que alcanzan los niños es visible gracias al gusto que manifiestan hacia ciertos textos más complejos. Por su parte, la mediadora 2 cataloga a este grupo de niños curiosos por avanzar en su proceso de lectura como «sabios lectores».

Esta evolución no es exclusiva del niño lector, sino que impacta también en los compañeros que leen con él, lo que se puede denominar una suerte de transferencia del gusto lector; es decir, van en búsqueda de nuevos contenidos, imágenes, textos y un material extra que ahora pueden manejar de manera más funcional con el objetivo de disfrutar de la lectura y de compartir con miembros de su comunidad. La transferencia del gusto lector es la séptima práctica lectora identificada porque significa que el niño está en capacidad de recomendar a otro nińo sobre lecturas que considera de calidad: «La niña $S$ escoge los libros. Primero, toma un libro del sector de cuentos para nińos, y lo deja en la mesa. Luego, vuelve a acercarse al estante y elige un libro que está en el atril. Le muestra ambos libros a la niña T y le recomienda» (observación, 10 diciembre de 2016). 
Por último, la relación que establece el usuario con el libro cuando frecuenta la sala influencia las prácticas de lectura que puede realizar durante su permanencia en ella. Las mediadoras observan que las prácticas de lectura cambian en función de la representación que los usuarios tienen de la misma y de las experiencias de lectura que han vivido. La mediadora 1 considera que «las prácticas lectoras tienen que ver con el azar y la idea de que sea totalmente libre (entrevista, 24 septiembre de 2016). En ocasiones estas formas de pensar las prácticas de lectura chocan o se confrontan con la visión que tienen los padres sobre la lectura, dado que ellos les brindan modelos de qué leer, dónde leer, cuándo leer y cómo leer. Entonces, si el niño descubre formas de leer distintas o se interesa por otro tipo de lecturas opuestas a los modelos que le han brindado y no encuentra una apertura para explorar estas prácticas, esta situación le puede generar desinterés o limitar su curiosidad por interactuar con el libro y descubrir nuevas prácticas de lectura (mediadora 2, entrevista, 10 septiembre de 2016). En síntesis, las prácticas lectoras que desarrollan los nińos implican un proceso de apropiación a nivel de la sala, mayores posibilidades de exploración y elección, reconocimiento de los materiales de lectura y su relación con las mediadoras.

\section{CONCLUSIONES}

La biblioteca infantil es un espacio donde el niño construye prácticas lectoras siempre que tenga un rol activo en la elección de los libros, se beneficie de las mediaciones de lectura, conozca diversos tipos de textos, tenga la posibilidad de hacer uso del espacio e interactuar con niños que frecuentan la sala. El proceso de exploración es fundamental para desarrollar prácticas de lectura y es una etapa necesaria en el proceso lector, inclusive puede ser considerada la primera práctica lectora que permite el acercamiento a los textos escritos. La mediación de lectura es una actividad necesaria en los programas de formación de lectores porque brinda acompañamiento permanente, ayuda al niño a vincularse con la sala y con otros lectores. El rol del mediador es complejo porque implica estar presente, y al mismo tiempo, ausente en el proceso de orientación y lectura de los libros.

Los indicadores que definen la apropiación de las prácticas lectoras en los usuarios de la biblioteca infantil estudiada son los niveles de exploración que puede alcanzar el lector asiduo, las formas de elección de un libro, así como las variadas maneras que existe para mediar las lecturas.

Los nińos menores de 6 años que aún no acuden a la escuela primaria desarrollan también prácticas lectoras iniciándose en la lectura e interpretación de las ilustraciones de los libros. Además, necesitan el acompañamiento 
del mediador con la actividad de lectura en voz alta porque tienen la oportunidad de escucharlo leer. Involucrar a los padres de familia es indispensable en este proceso, de manera que se les pueda dar orientaciones para que ellos participen de los procesos de exploración, elección y mediación de las lecturas.

El niño lector deviene con el tiempo un mediador de lectura y replica esta práctica en otros espacios. El ejercicio libre de la lectura es un derecho de todo niño lector.

\section{REFERENCIAS BIBLIOGRÁFICAS}

Aliagas, C. (2009). Aprendiendo a leer y a escribir con la canguro. En D. Cassany (ed.), Para ser letrados. Voces y miradas sobre la lectura (pp. 165-177). Barcelona: Paidós Educador.

Alzola, N. e Iturrioz, I. (2016). Del regazo a la palabra. Cuadernos de Pedagogía, (463), 23-26.

Cajaio, F. (2013). ¿Qué significa leer y escribir? En Ministerio de Educación Nacional (ed.), Leer para comprender, escribir para transformar: palabras que abren nuevos caminos en la escuela (pp. 53-61). Bogotá: Ministerio de Educación Nacional.

Casa de la Literatura Peruana, Minedu (2016). 10 años del Plan Lector: experiencias en la escuela. Reflexiones sobre la normativa. Lima: Casa de la Literatura Peruana.

Cassany, D. y Aliagas, C. (2009). Miradas y propuestas sobre la lectura. En D. Cassany (ed.), Para ser letrados. Voces y miradas sobre la lectura (pp. 13-22). Barcelona: Paidós Educador.

Escardó, M. (2012). Cuidando el proceso lector desde las bibliotecas. Ibersid, 6, 53-62.

Ferreiro, E. (2001). Pasado y presente de los verbos leer y escribir. Buenos Aires: Fondo de Cultura Económica.

Ferreiro, E. (2007). Nuevas perspectivas sobre los procesos de lectura y escritura. México: Siglo Veintiuno.

Ferreiro, E. (2011). Alfabetización. Teoría y práctica. México: Siglo Veintiuno.

Marlasca, B. (2015). El papel de la biblioteca pública en la formación de lectores. En S. Sánchez-García, S. Yuvero (eds.), Las bibliotecas en la formación del hábito lector (pp. 91-126). Cuenca: Universidad de Castilla-La Mancha.

Martin, C. D. y Ebrahim, H. B. (2016). Teachers' discourses of literacy as social practice in advantaged and disadvantaged early childhood contexts. South African Journal of Childhood Education, 6(2), 1-10. https://dx.doi. org/10.4102/sajce.v6i2.454 
Munita, F. (2015). El mediador escolar de lectura literaria. Un estudio del espacio de encuentro entre prácticas didácticas, sistema de creencias y trayectorias personales de lectura (Tesis para optar el grado de doctor). Universidad Autónoma de Barcelona, Barcelona.

Ortega, P. (2006). Comunidades y trayectorias de lectura en la biblioteca pública. Un estudio etnográfico en el municipio de Chalco, Estado de México. Revista Mexicana de Investigación Educativa, 11(28), enero-marzo, 293-315.

Patte, G. (2008). Déjenlos leer. Los niños y las bibliotecas. México: Fondo de Cultura Económica.

Petite, M. (2016). Leer el mundo. Experiencias actuales de transmisión cultural. México: Fondo de Cultura Económica.

Reyes, Y. (2007). La casa imaginaria: lectura y literatura en la primera infancia. Bogotá: Norma.

Reyes, Y. (2008). La biblioteca para los que «no saben leer»: acceso a libros y lecturas en la primera infancia. En R. E. Bonilla, D. Goldin y R. Salaberría (eds.), Bibliotecas y escuelas: retos y posibilidades en la sociedad del conocimiento (pp. 209-238). México, D.F: Océano Travesía.

Rodríguez, S. (2014). Ingresar a la cultura escrita y a las prácticas sociales del lenguaje, una configuración didáctica para el inicio de la escolaridad. Bogotá: Pontificia Universidad Javeriana.

Salaberría, R. (2009). Biblioteca escolar y bibliotecas públicas. En R. E. Bonilla, D. Goldin y R. Salaberría (eds.), Bibliotecas y escuelas: retos y posibilidades en la sociedad del conocimiento (pp. 445-462). México, D.F: Océano Travesía.

Slaby, M.H. (2014). Children's public library use and kindergarten literacy readiness in the state of Maryland (Thesis of Master of Library Science). University de Maryland, Estados Unidos.

Spedding, S., Harkins, J., Makin, L. y Whiteman, P. (2007). Investigating children's early literacy learning in family and community contexts. Review of the related literature. Adelaida, Australia: Office of Early Childhood and Statewide Services. Department of Education and Children's Services. Recuperado de https://www.education.sa.gov.au/sites/g/files/net691/f/ learning_together_lit_review.pdf

Yuvero, S. (2015). Lectura, bibliotecas y espacios lectores. En S. Sánchez-García y S. Yuvero (eds.), Las bibliotecas en la formación del hábito lector (pp. 9-24). Cuenca: Universidad de Castilla-La Mancha. 